\title{
Control Strategies for Combining Local Energy Storage with Wells Turbine Oscillating Water Column Devices
}

\author{
Salvador Ceballos, Judy Rea, Eider Robles, Iraide Lopez, Josep Pou and Dara O’Sullivan \\ Corresponding author telephone number: +34 664111184 E-mail: $\underline{\text { salvador.ceballos@tecnalia.com }}$
}

\begin{abstract}
This paper proposes three generator control strategies for Wells turbine-based floating oscillating water column (OWC) devices comprising electrical or mechanical energy storage systems. The first control strategy is indicated for low inertia turbine OWC devices that include ultracapacitors. This control law optimizes the power take-off efficiency by means of an instantaneous speed controller that allows variation of the turbine rotational speed in a wave-by-wave basis. In addition, the profile of the electrical power injected into the grid is smoothed, so that a high penetration of wave energy does not threaten the grid stability. The second and third control laws are developed for OWC systems comprising a flywheel. Quasi-constant and variable speed controllers are proposed. These control laws do not maximize the system efficiency but allow the use of simpler, smaller and cheaper power electronics. Additionally the power quality is also optimized. The development of the proposed control algorithms is accomplished by means of simulations and verified with an experimental test rig.
\end{abstract}

Keywords: Wave energy, Ocean Energy, Power electronics, Control of power converters, Energy storage, Oscillating water columns, Control of oscillating water columns. 


\section{Nomenclature}

\begin{tabular}{|c|c|c|c|}
\hline Symbol & Description & Symbol & Description \\
\hline$A_{d u c t}$ & $\begin{array}{l}\text { Turbine central hub cross-sectional } \\
\text { area }\end{array}$ & $L_{2}$ & Grid filter inductance \\
\hline$A_{h u b}$ & Turbine duct cross-sectional area & $p$ & Generator number of pair of poles \\
\hline$C$ & Ultracapacitor capacitance & $P_{g e n}$ & Generator power \\
\hline$C_{P}$ & Turbine efficiency coefficient & $\overline{P_{g e n}}$ & Mean value of the generator power \\
\hline$D$ & Turbine diameter & $P_{\text {grid }}$ & $\begin{array}{l}\text { Electrical power injected into the } \\
\text { grid }\end{array}$ \\
\hline$e_{d}$ & $d$-component of the grid voltage & $P_{m e c}$ & Mechanical power \\
\hline$e_{q}$ & $q$-component of the grid voltage & $P_{\text {OWCtest }}$ & $\begin{array}{l}\text { Pneumatic power at an optimum } \\
\text { level of damping }\end{array}$ \\
\hline$H$ & Inertial constant & $P_{\text {OWCtest }}^{\text {damping }_{i}}$ & $\begin{array}{l}\text { Pneumatic power at a discrete level } \\
\text { of damping }\end{array}$ \\
\hline$H_{S}$ & Significant wave height & $P_{\text {pneu }}$ & Actual pneumatic power \\
\hline$i_{1 d}$ & $\begin{array}{l}\text { Reactive component of the generator } \\
\text { current }\end{array}$ & $P_{r}$ & $\begin{array}{l}\text { Air pressure inside the } \mathrm{OWC} \\
\text { chamber }\end{array}$ \\
\hline$I_{1 d}^{*}$ & Generator reactive current reference & $Q$ & Volumetric air flow \\
\hline$i_{1 q}$ & $\begin{array}{l}\text { Active component of the generator } \\
\text { current }\end{array}$ & $T$ & Generator electrical torque \\
\hline$i_{1 q}^{*}$ & Generator active current reference & $T_{e}^{*}$ & Electrical torque reference \\
\hline$i_{2 d}$ & Active component of the grid current & $T_{P}$ & Peak wave period \\
\hline$i_{2 d}^{*}$ & Grid active current reference & $T_{w}$ & Window width of the MAF filter \\
\hline$i_{2 q}$ & $\begin{array}{l}\text { Reactive component of the grid } \\
\text { current }\end{array}$ & $v_{c a p}$ & Ultracapacitor voltage \\
\hline$I_{2 q}^{*}$ & Grid reactive current reference & $v_{1 d}$ & $\begin{array}{l}d \text {-component of the generator } \\
\text { voltage }\end{array}$ \\
\hline$K_{d}$ & Damping coefficient & $v_{1 q}$ & $\begin{array}{l}q \text {-component of the generator } \\
\text { voltage }\end{array}$ \\
\hline$K_{\text {turb }}$ & Pneumatic power attenuation function & $v_{2 d}$ & $\begin{array}{l}\text { d-component of the grid-connected } \\
\text { converter }\end{array}$ \\
\hline$L_{1}$ & Generator inductance & $v_{2 q}$ & $\begin{array}{l}\text { q-component of the grid-connected } \\
\text { converter }\end{array}$ \\
\hline
\end{tabular}




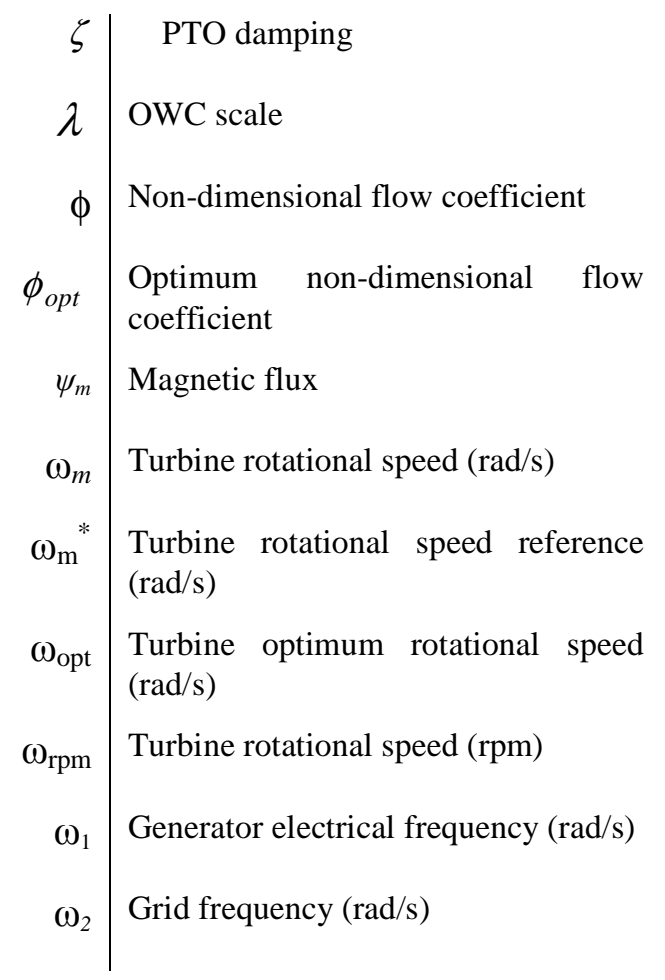

\section{Introduction}

The notion of converting the energy of ocean waves into more useful forms of energy, such as electrical energy, is not new. Over two hundred years ago, the first patent on an ocean energy harness technique was granted to a French engineer Pierre Girard [ HYPERLINK v "deG99" 1 ].

In more recent years, large European engineering companies and utilities have stepped up investment in the sector [2]. The growth potential presented by this expanding industry sector has been identified by policy makers. This potential is why, despite significant technical challenges (e.g. an optimum device type is yet to be determined), the industry continues to receive both financial and policy-level support from governments around the world. In 2013, the US Energy Department announced \$16 million for seventeen projects to help sustainably and efficiently capture energy from waves, tides and currents [3]. Also in 2013, The European Commission included specific funding supporting ocean energy devices at prototype and development stages [4]. The European Commission specifically stated in [5] that "improving the affordability, reliability, survivability, operability and stability of ocean energy devices is essential". The need for further research in the areas of grid connection and storage technologies is also explicitly mentioned [5]. 
This paper addresses two of these research areas, namely, grid integration considerations and storage technologies relating to a particular type of ocean energy convertor. Local on-device storage is considered in this paper, larger scale storage options are not examined.

Of the many different devices types that have been proposed, the oscillating water column (OWC) is one of the more mature technologies in terms of research input, full scale deployment and operational experience. OWC devices can be either shore-mounted fixed devices or moored floating devices. Several shoreline devices have been built and tested at full scale such as those at Pico [6] and Islay [7]. However due to a limitation in suitable sites, the future for large scale deployment of OWCs will rest with floating devices. Therefore, a floating OWC device is the focus of this paper. The power take off (PTO) element of OWC devices has been widely researched and various control law strategies have been presented and published. A summary of some of these control strategies is presented in [8].

In [8] fast-acting control strategies for low-inertia Wells turbine floating OWCs are presented. These strategies control the rotational speed of the turbine in a wave-by-wave basis in order to maintain the ratio between airflow and tip speed within the high efficiency range. Consequently, they allow an efficiency enhancement over averaged control techniques. However they can seriously challenge the grid stability since they can spoil the power quality.

This paper introduces several control approaches for Wells turbine-based OWCs that include electrical and mechanical energy storage systems. Ultracapacitors and flywheels are considered as energy storage elements and their effects in the power quality and system efficiency are assessed. The proposed control strategies are developed using simulation models based on wave tank experiments of a floating OWC device at several discrete levels of damping. Experimental verification of the results in an electrical test rig is also presented.

The paper is organized as follows. Section 3 describes the operation of the OWC and the Wells turbine. In Section 4 the resource input data and OWC modeling approach are detailed. Section 5 introduces three control strategies for Wells turbine-based OWC devices comprising ultracapacitors and flywheels and Section 6 compares them. Finally Section 7 presents experimental results and Section 8 concludes the paper.

\section{Device and Power Take Off Description}

An OWC consists of a hollow semi-submerged structure with an underwater opening that allows sea water to enter and leave the device and thereby compressing the trapped mass of air in the air chamber. 
This pressure change causes air to flow across an air turbine in the device's air duct. The structure type examined in this paper is shown in Fig 1 and is identical to that described in [8].

The pressure changes that occur are a function of wave amplitude and frequency and of the damping of the system. Optimal power transfer generally occurs over a limited range of applied PTO damping, and the PTO system is usually designed to operate within this damping range for the majority of its control regime. The PTO system examined in this paper consists of a fixed pitch Wells turbine without guide vanes, a permanent magnet synchronous generator (PMSG) and a back-to-back power converter. This paper does not consider the use of controllable pressure relief valves.

A typical Wells turbine efficiency curve is depicted in Fig. 2. The non-dimensional flow coefficient, $\phi$, is equivalent to the air velocity to tip velocity ratio and can be expressed as:

$$
\phi=\frac{2 Q(t)}{\left(A_{\text {duct }}-A_{\text {hub }}\right) D \omega_{m}(t)}
$$

where $Q$ is the volumetric air flow across the turbine, $A_{\text {duct }}$ and $A_{\text {hub }}$ are the turbine duct and central hub cross-sectional areas respectively, $D$ is the turbine diameter, and $\omega_{\mathrm{m}}$ is the turbine rotational speed in $\mathrm{rad} / \mathrm{s}$.

From this expression, it is clear that the turbine performance is related to the instantaneous air flow, which varies widely over each wave cycle. In general, the volumetric flow is itself related to the turbine velocity via the turbine damping, and also to the wave input. The turbine rotational speed represents the main control variable by which the instantaneous operating point of the turbine can be manipulated.

\section{Wave Resource and Pneumatic Power Input Data}

The wave climate at a particular location can be represented by a bi-variate scatter plot of wave height and wave period. These plots display the occurrence of different sea-states from annual (or multi-annual) wave data gathered at a site. An individual sea-state is represented by a significant wave height, $H_{S}$, and peak wave period, $T_{P}$ when measured over a set time window (typically 30-60 minutes).

The hydrodynamic response of the OWC to different sea states has an impact on the PTO and ultimately on overall energy yield. Therefore, this response needs to be understood and modeled. This can be achieved by either (i) full numerical modeling of the hydrodynamic-aerodynamic of a floating OWC or (ii) experimentally gathered data from scaled device testing. The former is highly complex and the challenges of this approach are described in [9]. The latter approach was used to generate the model for this paper. 


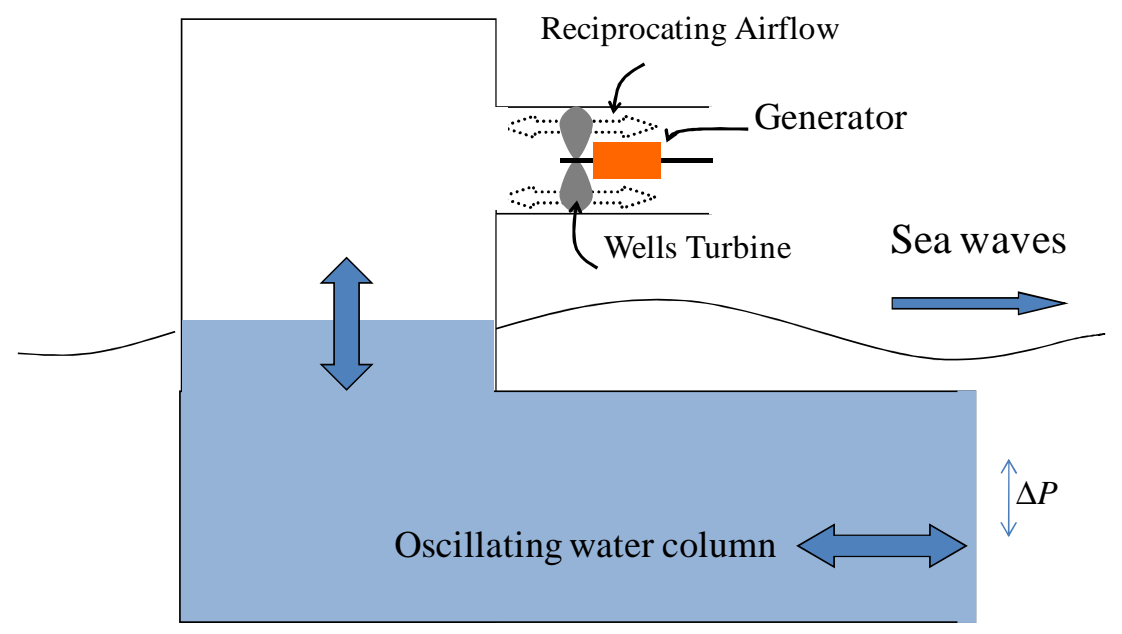

Fig. 1: Illustration of OWC operating principle.

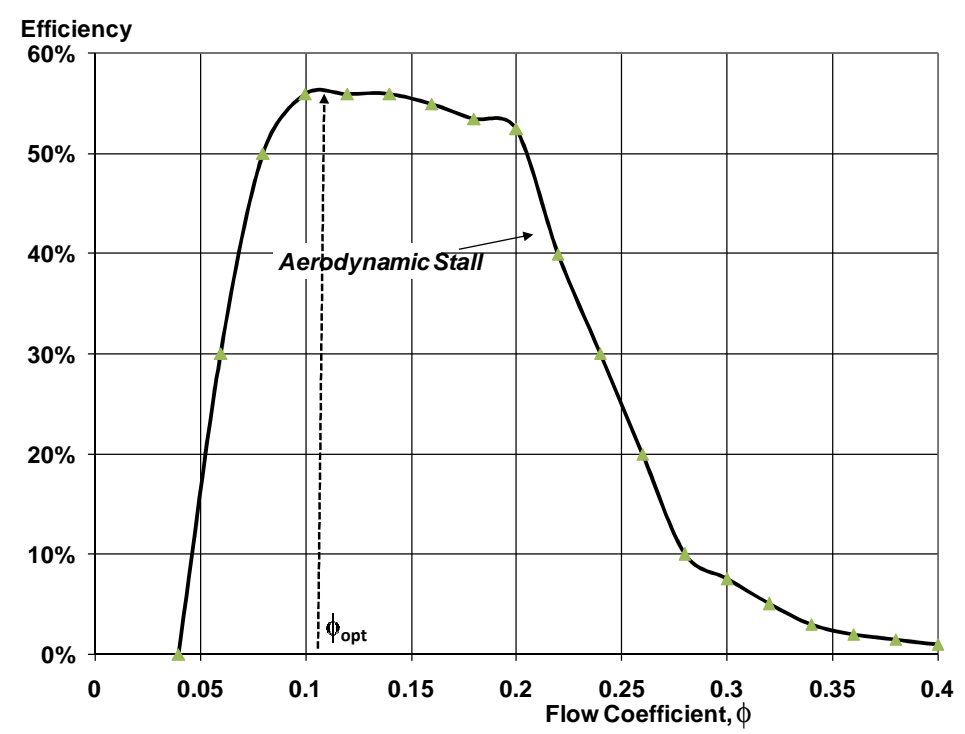

Fig. 2: Wells turbine performance characteristic.

A floating OWC device has been tested in the HMRC wave basin at a scale of 1:50. Since it is not feasible to include the PTO elements (air-turbine generator) in models of this scale; instead the effect of the PTO is modelled by recording the OWC response at several discrete levels of damping.

Extensive wave basin tests yield two distinct datasets of results that are used in this paper; (i) pneumatic power time series of an optimally damped OWC for different sea states and (ii) characterization of the relationship between the pneumatic power and damping. The first dataset was derived as follows. The scaled device model was tested with various levels of damping over a wide range of Bret-Schneider sea states. For each sea-state, a set of pneumatic power time series were calculated (based on measured

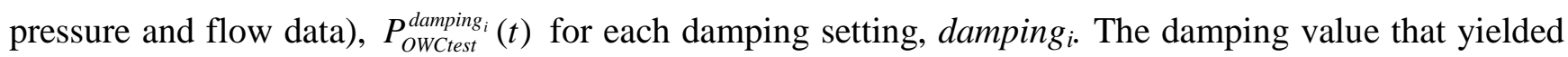
the largest average pneumatic power for that sea-state was defined as the optimum damping. The 
relationship between the pneumatic power time series at optimum damping level, $P_{\text {OWCtest }}(t)$, and the pneumatic power at the actual damping level, $P_{\text {pneu }}(t)$, is characterized by an experimentally derived empirical attenuation function $k_{t u r b}$. Consequently, the pneumatic power at the actual damping level for the purposes of the model is given by:

$$
P_{\text {pпеи }}(t)=\lambda^{3.5} P_{\text {OWCtest }}(t) k_{\text {turb }}(\zeta)
$$

where $P_{\text {OWCtest }}(t)$ is the time series pneumatic power output from the wave basin test data at optimum damping level, $k_{\text {turb }}$ is the empirically derived attenuation function scaled, which is related to PTO damping, $\zeta$ and thus to turbine rotational speed; $\lambda$ is the scale of the OWC model e.g. for a 1:50 scale model, $\lambda$ equals 50 . The scaling relationship for power $\left(\lambda^{3.5}\right)$ is based on the method of Froude scaling [10].

For the analysed OWC, there is a range where the damping factors, and consequently the turbine rotational speeds, do not have a significant influence on the average pneumatic power. For rotational speeds within this range, the average pneumatic power is close to the optimum. The variations of the rotational speed allowed in the variable speed control strategies developed in next section are within this range. Therefore the average pneumatic power production is maximized.

\section{Control Strategies}

The primary aim of PTO control laws, is usually the optimization of turbine efficiency. However, due to the pulsating nature of the wave energy, the power injected into the grid is highly variable. This fact may seriously affect the grid stability. Additionally the power electronics of the PTO system have to be overrated to withstand high power peaks. This issue is well discussed in [11] and [12].

In this section energy storage systems are introduced in order to smooth the electrical power injected into the grid. Both, electrical and mechanical energy storage elements are considered. Three different control strategies for a Wells turbine OWC device are presented. The primary goal of these control strategies is to smooth the profile of the electrical power injected into the grid, so that a high penetration of wave energy does not threaten the grid stability; optimization of turbine efficiency is also considered, but as a secondary goal.

The control strategies require the turbine rotational speed to vary within a wide range. Consequently, the PTO system considered in the paper uses a fully variable speed architecture comprising a fixed pitch Wells turbine, a PMSG and a back-to-back power converter (see Fig. 3). 


\section{A. Optimum Speed Control for Turbines with Ultracapacitor Energy Storage}

This sub-section analyses the use of ultracapacitors to store energy and smooth the electrical power supplied by the OWC to the grid. The ultracapacitors are connected to the back-to-back dc-bus through a dc/dc power converter (see Fig. 3). To control such a system three different controllers are needed; one for each power converter. Out of these three controllers, only the generator side and the grid side power converter controllers have elements specific to this particular application. A detailed description of these controllers is given below. The third controller, the $\mathrm{dc} / \mathrm{dc}$ controller, maintains the dc-bus voltage fixed to a constant value. Since this type of controller is well reported in the technical literature [13]-[14], it is not described here.

\section{A.1) Generator-side converter controller}

The generator-side converter controller ensures that the rotational speed of the mechanical system tracks the rotational speed reference. A Field Oriented Control (FOC) is used for this purpose. The block diagram representation of this controller is shown in Fig. 4. This controller is well described in [8] where the performance of the FOC and some practical rules to tune the proportional-integral (PI) current controllers are presented.

The rotational speed reference, $\omega^{*}$, that is used as an input to the FOC is calculated with the objective of optimizing the turbine efficiency in a wave period basis. Fig. 2 shows the efficiency curve of a Wells turbine. It can be seen that the maximum turbine efficiency is achieved at an optimum non-dimensional flow coefficient, $\phi_{\text {opt }}$, as marked in Fig. 2.

Consequently, in accordance with (1), if the rotational speed of the turbine is adjusted according to the air flow in every wave period, it is possible to instantaneously fix the non-dimensional flow to its optimum value, thus maximizing the turbine efficiency.

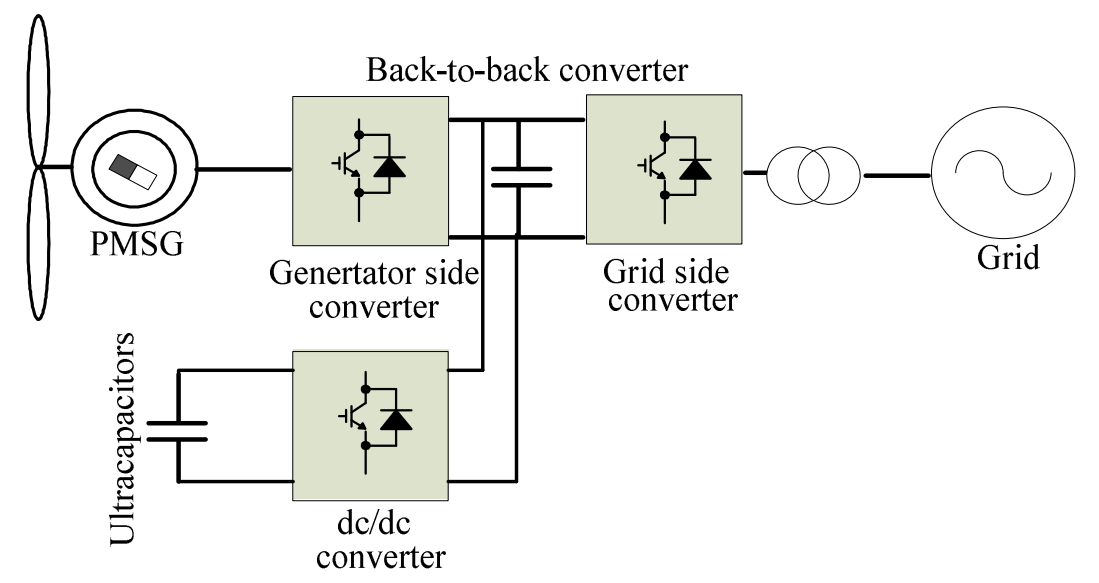

Fig. 3: PTO system. 
Expression (1) can be rewritten at the optimum point as follows:

$$
\phi_{\text {opt }}=\frac{2 Q(t)}{\left(A_{\text {duct }}-A_{\text {hub }}\right) D \omega_{\text {opt }}(t)}
$$

where $\omega_{\text {opt }}$ is the turbine optimum angular speed for maximum mechanical power output.

The instantaneous air flow $Q(t)$ through a Wells turbine can be expressed as a function of the instantaneous pneumatic power $P_{\text {pneu }}(t)$ as follows:

$$
Q=\sqrt{\frac{P_{\text {рпеи }}(t)}{K_{d} \omega_{m}(t)}}
$$

where $K_{d}$ is a coefficient that relates the turbine damping to the turbine angular speed. In the case of a Wells turbine, this is approximately a linear relationship [15], so that $K_{d}$ can be represented by a constant.

Substituting (4) into (3), and removing the time functionality $(t)$ for conciseness, the non-dimensional flow coefficient can be expressed as:

$$
\phi_{\text {opt }}=\frac{2 \sqrt{\frac{P_{\text {pneu }}}{K_{d}}}}{\left(A_{\text {duct }}-A_{\text {hub }}\right) D \omega_{o p t}^{1.5}}
$$

Therefore,

$$
\omega_{o p t}=\left(\frac{2 \sqrt{\frac{P_{p n e u}}{K_{d}}}}{\left(A_{d u c t}-A_{h u b}\right) D \phi_{o p t}}\right)^{\frac{2}{3}}
$$

The pneumatic power $P_{\text {рпеи }}$ can be estimated as a function of the measured air pressure inside the chamber $P_{r}$ and the actual angular speed of the turbine by expression (7).

$$
P_{\text {pneu }}=\frac{P_{r}^{2}}{K_{d} \omega_{m}}
$$

Substituting (7) into (6), the optimal rotational speed reference that optimizes the turbine efficiency in a wave-by-wave basis can be analytically calculated as follows:

$$
\omega_{\text {opt }}=\left(\frac{2 P_{r}}{\left(A_{d u c t}-A_{h u b}\right) K_{d} D \phi_{o p t} \sqrt{\omega_{m}}}\right)^{\frac{2}{3}}
$$


Equation (8) calculates the optimum rotational speed reference as a function of the air pressure and the actual rotational speed of the turbine. Both magnitudes are known, since they can be measured with the corresponding sensors. Once calculated, the optimum speed reference is used as the input of the FOC represented in Fig. 4.

\section{A.2) Grid-side converter controller}

In typical applications where back-to-back power converters are used, the controller of the grid side converter usually maintains the dc-bus voltage fixed to a constant value. A voltage oriented controller (VOC) can be used with this purpose.

However, when ultracapacitors are used, the VOC scheme has to be modified. To benefit from the energy storage capabilities of the ultracapacitor, the dc-bus voltage is no longer controlled with the grid side converter. Fig. 5 shows the structure of the proposed grid side converter controller used when ultracapacitors are employed.

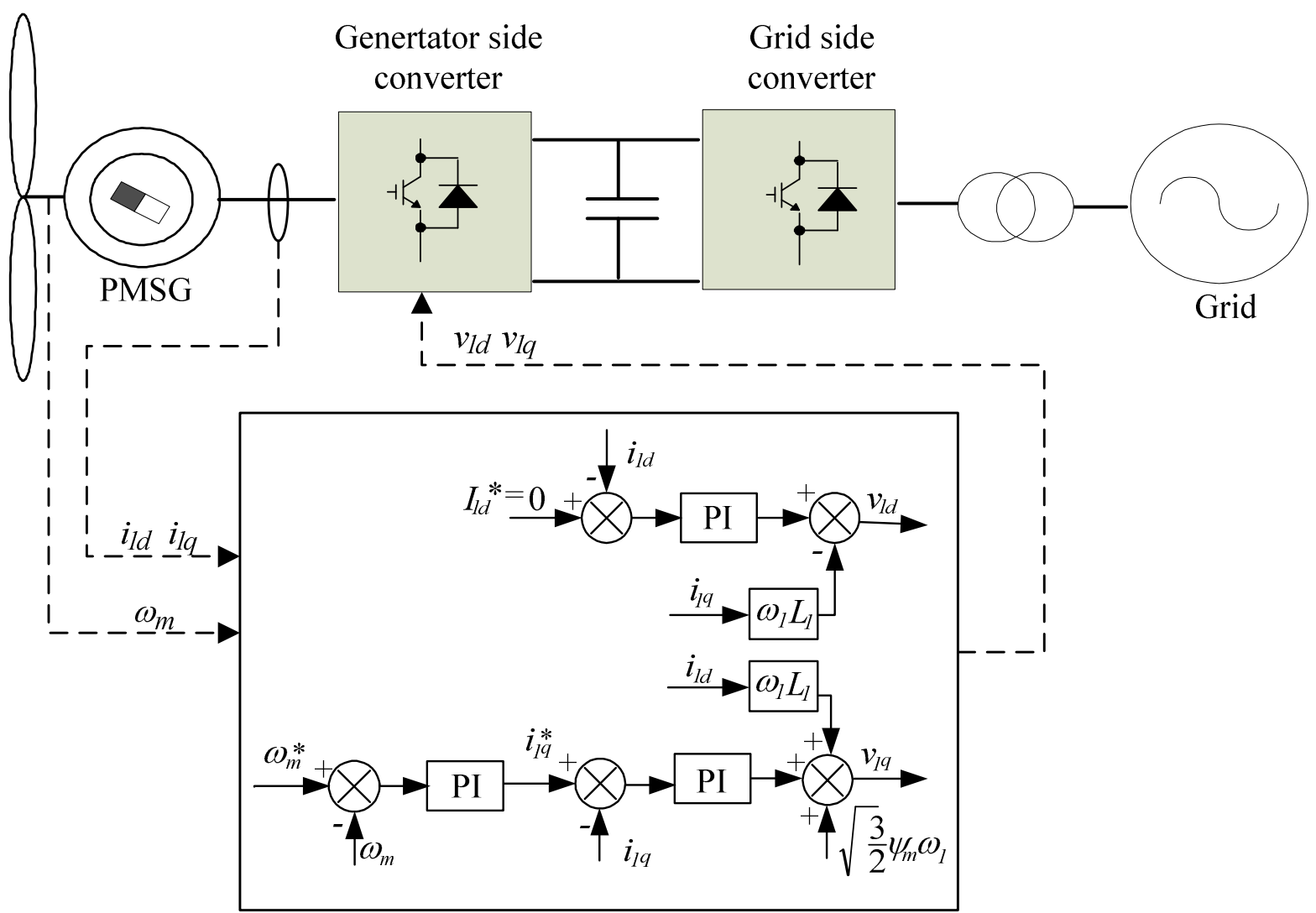

Genertator side converter controller

Fig. 4: Generator side converter controller. FOC block diagram representation. The dc/dc converter has been removed for illustration simplicity. $i_{l d}$ and $i_{l q}$ are the reactive and active components of the actual generator current, $I_{l d}{ }^{*}$ and $i_{l q}{ }^{*}$ are the reactive and active current references, $\psi_{m}$ is the magnetic flux, $L_{l}$ is the generator inductance, $\omega_{1}$ the generator electrical frequency, $\omega_{\mathrm{m}}$ the generator actual speed, $\omega_{\mathrm{m}}{ }^{*}$ the generator speed reference and $v_{l d}$ and $v_{l q}$ are the $d q$ components of the voltage at the generator terminals. 
The voltage regulator of the VOC has been removed and the reference of the active current that the converter injects into the grid $\left(i_{2 d}^{*}\right)$ is now calculated by a moving average filter (MAF) applied over the generator electrical power. The MAF provides the mean value of the generator electrical power between the instants $t-T_{W}$ and $t$ as described in equation (9):

$$
\bar{P}_{g e n}=\frac{1}{T_{W}} \int_{t-T_{W}}^{t} P_{g e n} d t
$$

where $P_{g e n}$ is the generator electrical power, that can be calculated via the measurement of the generator ac voltage and ac current, and $T_{W}$ is the MAF window width.

Therefore the power injected into the grid is equal to the mean power of the generator over a certain time window $T_{W}$. Consequently, the grid power is smoothed, avoiding the high power peaks. These high power

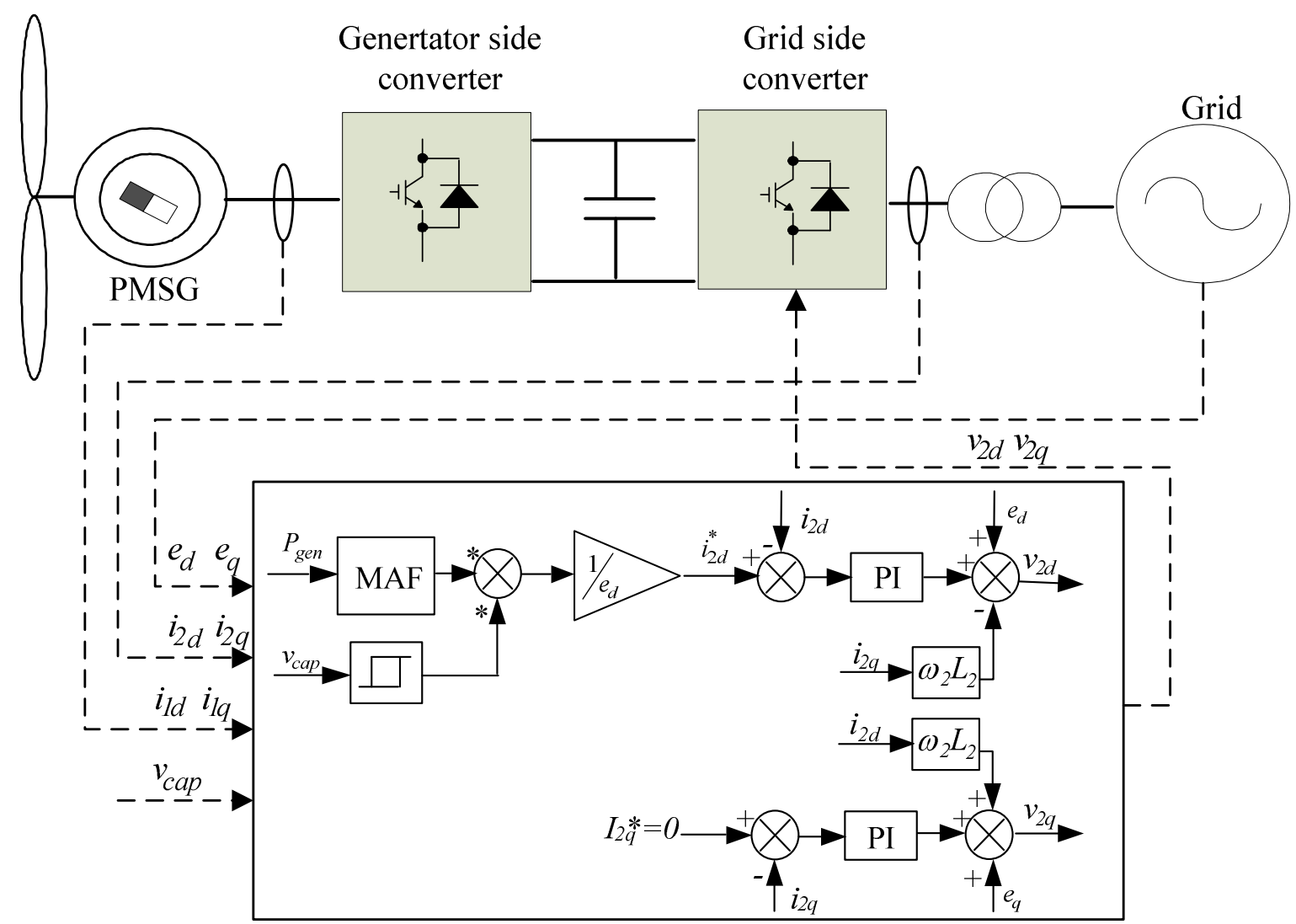

Grid side converter controller

Fig. 5: Grid side converter controller with ultracapacitors. Block diagram representation. The dc/dc converter has been removed for illustration simplicity. $P_{g e n}$ is the generator power, $v_{c a p}$ is the ultracapacitor voltage, $i_{2 d}$ and $i_{2 q}$ are

the active and reactive components of the actual grid current, $i_{2 d}{ }^{*}$ and $I_{2 \mathrm{~d}}{ }^{*}$ are the active and reactive current references, $e_{d}$ and $e_{q}$ are the active and reactive components of the grid voltage, $\omega_{2}$ is the grid frequency, $L_{2}$ is the inductance of the grid filter and $v_{2 d}$ and $v_{2 q}$ are the $d q$ components of the voltage at the grid-side converter terminals. 
peaks are absorbed by the ultracapacitors given that the dc/dc converter maintains the dc-voltage fixed to a constant value. This control algorithm performs well providing that the converter efficiency is $100 \%$. However, this is not the case in a real application. In order to compensate for the converter losses, the output of the MAF is corrected with a hysteresis gain. If the ultracapacitor voltage is below a defined minimum limit, the output of the MAF is multiplied by a factor a little bit lower than the power converter efficiency (a typical value for this factor could be around 0.9). This is done in order to compensate for the converter and grid filter losses, thus avoiding a slow discharge of the ultracapacitors. Once $i^{*}{ }_{2 d}$ has been calculated, it is used as an input to a current controller similar to that used in a well-known VOC.

A detailed model comprising the OWC air chamber, a Wells turbine, a PMSG and a back-to-back converter, as well as the control algorithm described above has been developed using Matlab/Simulink. The response of the OWC to the wave input does not form part of the model - this aspect of the system is derived from the experimental testing. The pneumatic power time series at the optimum damping level, as obtained from the wave basin tests and described in section 4, provides the input time series to the model, where it is then attenuated according to (2) to account for the actual damping of the turbine model. The actual wave elevation time series applied to the physical model in the wave basin are based on Bretschneider-type irregular sea states, typical of open ocean conditions [16] with a random phase shift associated with each of the spectral components. The significant wave height, $H_{S}$, and peak wave period, $T_{P}$, of the different sea states used for simulations are shown in Table I.

TABLE 1

SIGNIFICANT WAVE HEIGHT, HS, AND PEAK WAVE PERIOD OF THE SEA STATES

\begin{tabular}{c|c|c} 
Sea & $H_{s}(\mathrm{~m})$ & $T_{P}(\mathrm{~s})$ \\
State & & \\
\hline B02 & 3 & 7.1 \\
\hline B04 & 3 & 8.5 \\
\hline B06 & 3 & 10.6 \\
\hline B07 & 5 & 10.6 \\
\hline
\end{tabular}

\begin{tabular}{c|c|c}
$\begin{array}{c}\text { Sea } \\
\text { State }\end{array}$ & $H_{s}(\mathrm{~m})$ & $T_{P}(\mathrm{~s})$ \\
\hline $\mathrm{B} 09$ & 5 & 12.7 \\
\hline $\mathrm{B} 12$ & 3 & 14.1 \\
\hline $\mathrm{B} 13$ & 7 & 14.1 \\
\hline $\mathrm{B} 15$ & 5 & 17.7 \\
\hline \multicolumn{3}{|c}{}
\end{tabular}

The PTO is represented by means of a one-mass model. This assumption seems reasonable since the rotational stiffness of a typical shaft for this system is high enough to make negligible the effects caused by resonances. To implement the MAF in the discrete-time domain, the backward Euler integration method has been used. A rectangular time window has been assumed to perform the MAF calculations.

Simulation results are shown in Fig. 6. Fig 6(a) shows the pneumatic power inside the OWC chamber when sea state B13 is considered. The pulsating nature of the pneumatic power is clearly manifested in this figure. Part of the pneumatic power is captured by the Wells turbine and transferred into mechanical power on the shaft. Fig. 6(b) and 6(c) show the mechanical power and the generator electrical torque 
respectively. At this point, it is worth noting two facts. Firstly, since the rotational speed of the turbine is calculated according to (8), the turbine efficiency is maximized in a wave-by-wave basis. Consequently, the mechanical power represented in Fig. 6(b) is the maximum power that a control law can provide. Secondly, the highly pulsating nature of the mechanical power and the electrical torque is also manifested. This fact makes necessary to overrate the generator and the generator side and $\mathrm{dc} / \mathrm{dc}$ power converters. Thus, this control law optimizes the turbine efficiency but increases the power demands on the generator and the converters. Fig. 6(d) shows the power injected into the grid. The filtering effect of ultracapacitors is clearly visible. Smoothing the power variations in this way ultimately improves the power quality. Lastly, Fig. 6(e) displays the ultracapacitor voltage. As expected the voltage is varying continuously as a function of the sea conditions, thus allowing storing energy in the ultracapacitors.

The data represented in Fig. 6 have been obtained using a MAF window width $T_{W}=30 \mathrm{~s}$ and an ultracapacitor capacitance $C=40 \mathrm{~F}$. These values arise as a trade-off between the filtering effect of the grid power and the size of the ultracapacitors. As $T_{W}$ reduces, the filtering effect decreases and a lower capacitance is required. Obviously the selected values depend on the wave climate of a specific location and cannot be taken as general figures. It is necessary to simulate all the sea states of a specific site to define the optimum values of MAF window width and capacitance.

Finally, it is important to point out that this control law is only applicable to low inertia and low friction PTO systems. If the inertial constant of the turbine is lower than $H=2 \mathrm{~s}$, the speed reference given by (8) can be accurately followed and the turbine efficiency is optimized. Otherwise it is not possible to follow the optimum speed reference command in a wave-by-wave basis and the system would not perform correctly.

\section{B. Moving Average Filter Based Controller for Turbines with Mechanical Storage using a Flywheel}

This sub-section analyses the use of a flywheel as a way to store energy and filter the output power. The flywheel can be implemented simply by increasing the mass of the turbine or alternatively by linking the turbine with a cylindrical body with a given dimensions and weight. It is not necessary to use more sophisticated flywheels.

If a flywheel is used, the grid side converter can be controlled using a standard VOC. Since this controller is well reported in the technical literature [8], it is not described in this paper. However, the controller of the generator side converter has to be specifically developed for this application. Therefore, a comprehensive explanation about this controller is given in the following section. 


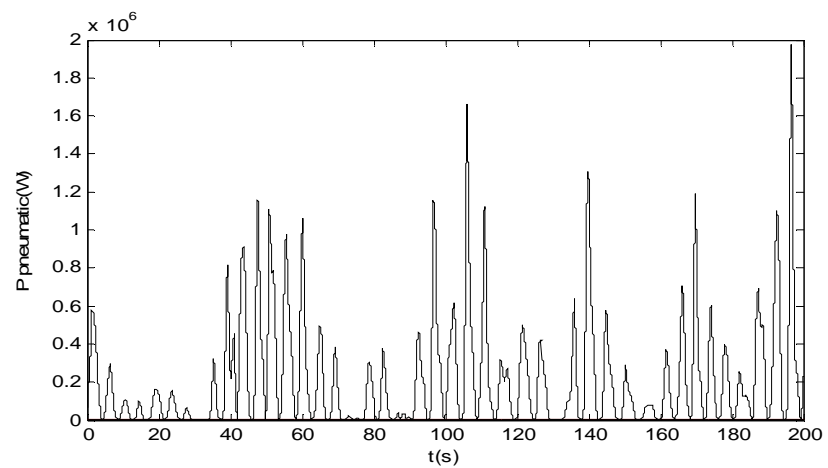

(a)

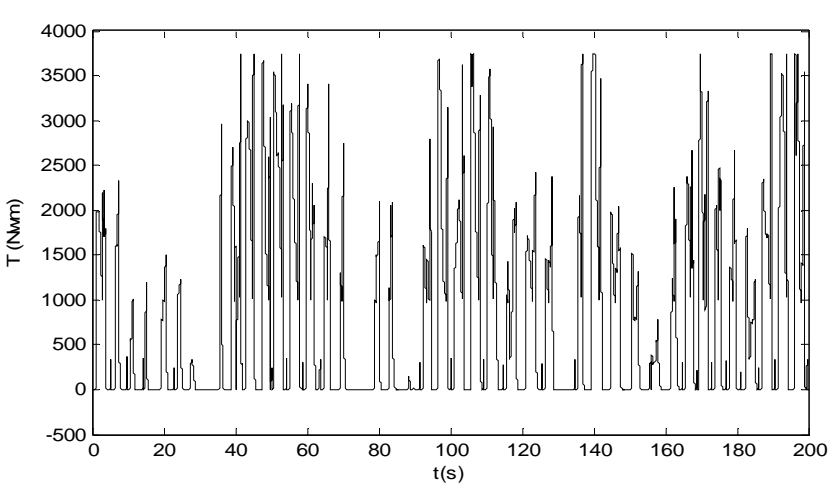

(c)

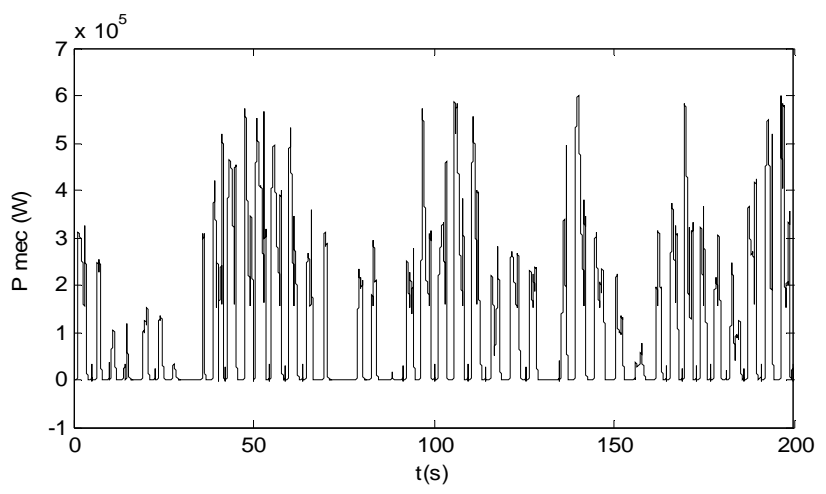

(b)

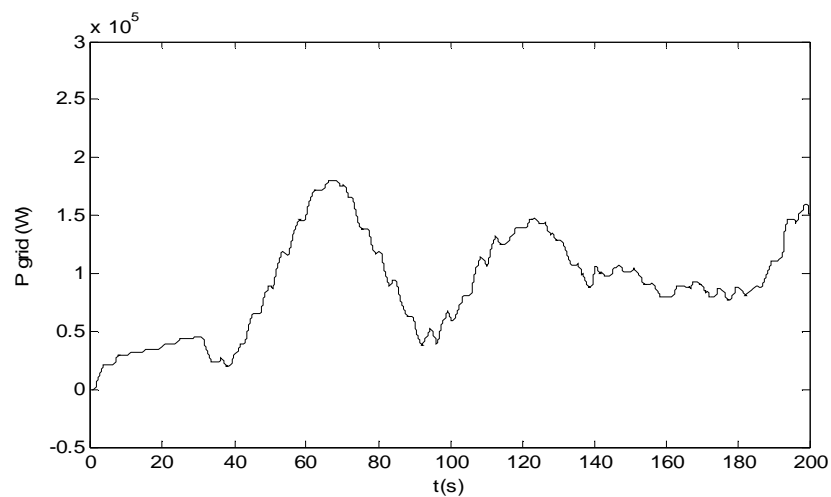

(d)

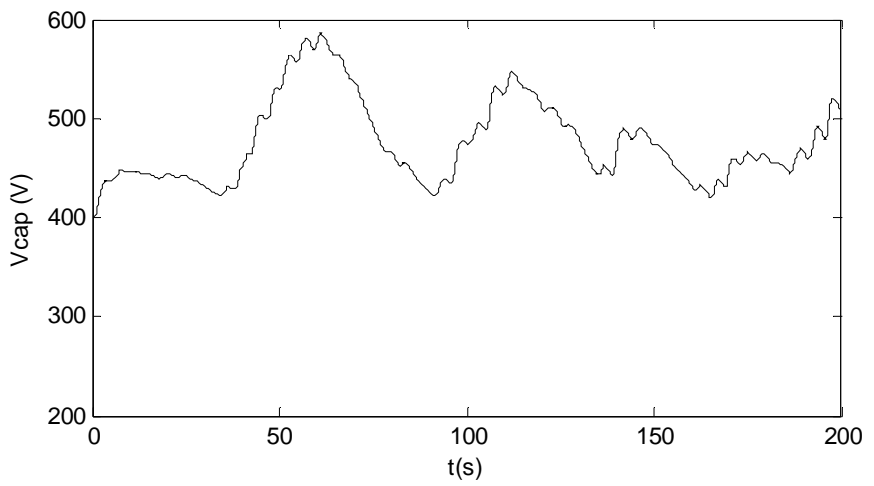

(e)

Fig. 6: Simulation results under sea state B13. Ultracaps. (a) Pneumatic power; (b) Mechanical power; (c) Electrical toque; (d) Grid power; (e) Ultracapacitors voltage.

\section{B.1) Generator side converter controller}

The control method described in this section has some similarities to the method that used ultracapacitors.

In this case, when a flywheel is used, it is not possible to directly control the turbine speed. Otherwise, no benefit from the use of a flywheel is obtained. Consequently the FOC scheme shown in Fig. 4 needs to be modified. Fig. 7 shows the new structure of the generator controller. The speed regulator has been removed and the active current reference $i_{1 q}^{*}$ is obtained from a MAF filter applied over the mechanical 
power supplied by the turbine. This magnitude is not directly measurable, but it can be estimated. The mechanical power captured by the Wells turbine can be expressed as follows:

$$
P_{\text {mec }}=P_{\text {pпеu }} C_{p}(\phi)
$$

where $P_{\text {mec }}$ is the mechanical power, $P_{\text {pneu }}$ is the pneumatic power and $C_{p}(\phi)$ is the turbine efficiency characteristic represented in Fig. 2.

The pneumatic power $P_{\text {рneu }}$ and the non-dimensional flow coefficient $\phi$, can be estimated as a function of the air pressure inside the chamber $P_{r}$ and the actual angular speed of the turbine using (7) and (11) respectively.

$$
\phi=\frac{2 P_{r}}{\left(A_{d u c t}-A_{h u b}\right) K_{d} D \omega_{m}^{2}}
$$

Substituting (7) and (11) into (10), (12) is obtained.

$$
P_{\text {mec }}=\frac{P_{r}^{2}}{K_{d} \omega_{m}} C_{p}\left(P_{r}, \omega_{m}\right)
$$

This expression allows the estimation of the mechanical power as function of the air pressure inside the chamber, the rotational speed and the turbine power coefficient curve. All these magnitudes are known or can be measured, thus allowing the calculation of the mechanical power. Once the mechanical power is estimated, its mean value is calculated using a MAF and it is taken as a reference to calculate, first the electrical torque of the generator, and then the reference of the active current $\left(i^{*}{ }_{1 q}\right)$ (see Fig. 7). Therefore the generator electrical power is equal to the mean value of the estimated mechanical power. Consequently, the generator electrical power is smoothed. It is also important to remark that the mean value of the estimated mechanical power is corrected with a hysteresis gain. If the rotational speed of the turbine is below a defined minimum limit, the estimated mean value of the mechanical power is multiplied by 0.9. Similarly, if the speed is over a defined maximum limit the mean value of the mechanical power is multiplied by 1.1. This is done in order to compensate the errors while estimating the mechanical power with expression (12) and the power losses.

Once $i_{1 q}^{*}$ has been calculated, it is used as an input of a current controller similar to that used in a wellknown FOC, [8]. Fig. 8(a) and (b) display the electrical power and the generator electrical torque for the same sea state represented in Fig. 6 when an inertia of $800 \mathrm{kgm}^{2}$ and a window width $T_{W}=30 \mathrm{~s}$ are assumed. These values arise as a trade-off between the filtering effect of the MAF and the size of the flywheel. The higher the $T_{w}$, the greater the filtering effect of the MAF. Consequently, a bigger inertia is 


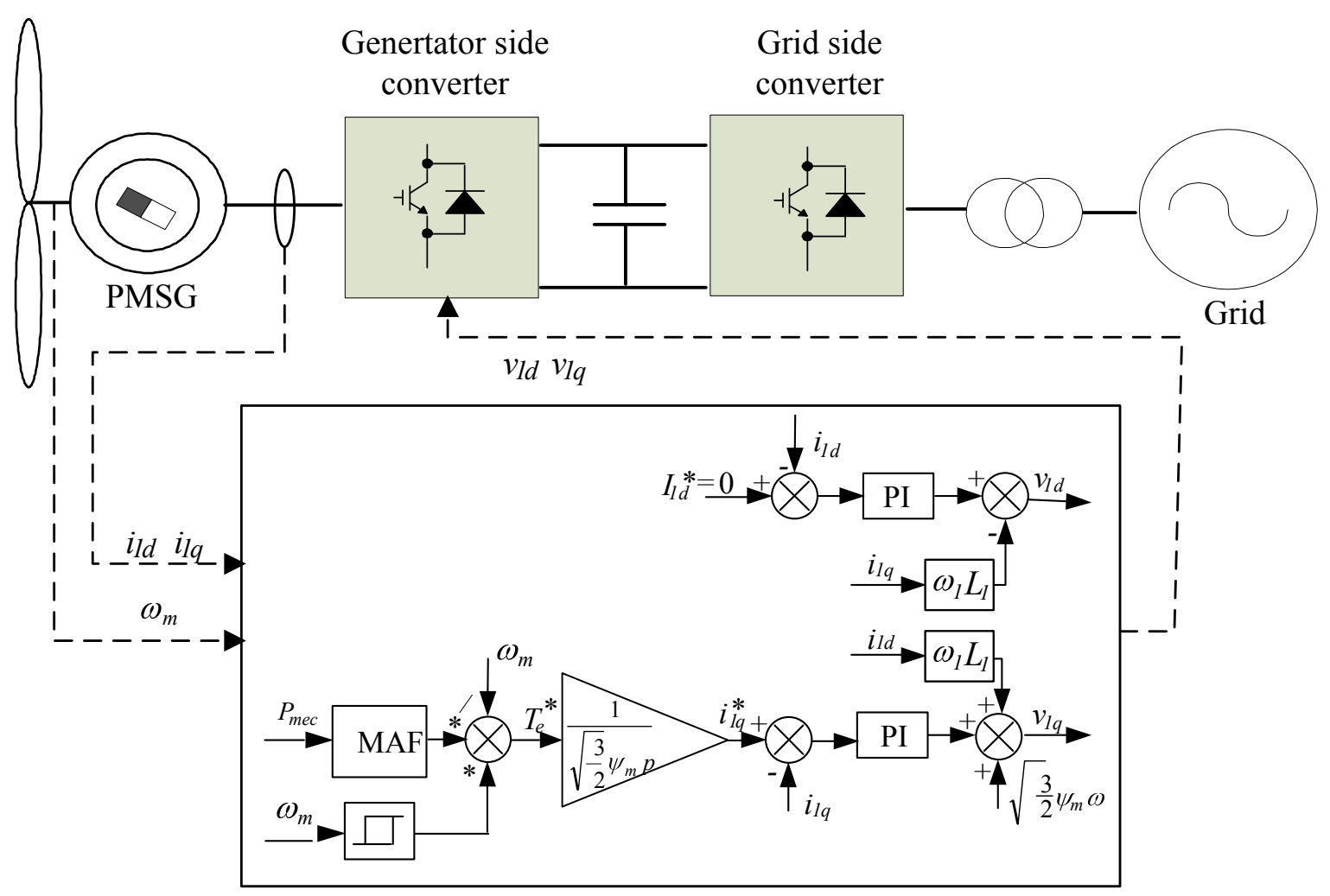

Genertator side converter controller

Fig. 7: Generator side converter controller when a flywheel is used. Block diagram representation. $\mathrm{P}_{\text {mec }}$ is the mechanical power, $i_{l d}$ and $i_{l q}$ are the reactive and active components of the actual generator current, $I_{l d}{ }^{*}$ and $i_{l d}{ }^{*}$ are the reactive and active current references, $\psi_{m}$ is the magnetic flux, $L_{l}$ is the generator inductance, $\omega_{1}$ the generator electrical frequency, $\omega_{\mathrm{m}}$ the generator actual speed, $\omega_{\mathrm{m}}{ }^{*}$ the generator speed reference, $p$ the number of pair of poles of the generator, and $v_{l d}$ and $v_{l q}$ are the $d q$ components of the voltage at the generator terminals.

required. The values of $T_{w}$ and the inertia have been selected through the simulation of all the sea states representative of the wave climate of the specific site considered in the paper. The one-mass model assumption has also been made here. The electrical power and torque are filtered and do not present high peaks. Therefore, neither the converters nor the generator have to be overrated when a flywheel is used. Finally, Fig. 8(c) shows the turbine speed for a high energy (B13) and a low energy (B06) sea state. In both cases the turbine speed is varying slowly around a defined speed reference (1400 rpm). This speed reference is indirectly followed by the effect of the hysteresis gain introduced in the controller. Whenever the rotational speed is below a defined minimum limit, the hysteresis gain is set to 0.9 . The minimum limit used in the simulations has been set to $1300 \mathrm{rpm}$. Consequently, the generator electrical power is lower than the mechanical power captured by the turbine and the rotational speed tends to increase. The opposite behaviour is achieved if the rotational speed is above a defined maximum limit. If the speed is above $1500 \mathrm{rpm}$, the hysteresis gain is set to 1.1 and the rotational speed tends to decrease. The speed 
reference is calculated to optimize the turbine efficiency, provided that, with this control strategy, the turbine speed is quasi-constant for any sea state. The speed reference value has been obtained through offline simulations of all the sea states considering their respective occurrences. Several fixed speeds have been tested and it has been found that $1400 \mathrm{rpm}$ is the fixed optimum speed to maximize the energy produced over one year for the sea climate of the site analysed in this paper.

\section{Torque-Speed Curve Based Controller for Turbines with Mechanical Storage using a Flywheel}

The main drawback of the control algorithm described in the previous sub-section is that the rotational speed is almost constant around a defined fixed speed under any sea state.

Even though an optimum fixed speed is selected, the efficiency obtained with this control law is lower than the efficiency of an equivalent variable speed solution. Therefore, it seems advantageous from an energetic point of view to develop a variable speed solution when a flywheel is used. Obviously, in this case, it is not possible to follow the speed reference given by (8) in a wave-by-wave basis due to the effect of the high inertia. However, it is possible to develop a control law that changes the turbine rotational speed in a sea state by sea state basis. In this case, the rotational speed of the turbine will change until it reaches an optimum value according to the current sea state. It would also be desirable that the speed changes occur automatically without any information or measurement about the sea state.

Table 2 shows the optimum speed on a sea state basis, the mean power and the mean torque for every sea state representative of a given wave climate. The optimum speed values have been obtained through offline simulations. Several fixed speeds have been tested for every sea state and the particular speed that maximizes the efficiency has been selected. Based on the data available in Table 2, it is possible to develop a torque-speed characteristic curve. This curve will allow the estimation of the optimum reference torque for a given rotational speed, thus optimizing the turbine efficiency. For the proposed case study, the torque-speed curve can be approximated by the following expression:

$$
T=3.10^{-4} \omega_{r p m}^{2}-0.1047 \omega_{r p m}+1.1454
$$

where $\omega_{r p m}$ is the rotational speed in rpm.

Once the torque-speed curve has been calculated, it is included in the controller. The block diagram of this controller is shown in Fig. 9. This architecture is used to control the generator side converter.

Fig. 10 displays the simulated rotational speed for the same two sea states employed in the previous subsection. In this case the rotational speed is different for both sea states as opposed to those of previous law 
TABLE 2

SEA STATE FIGURES: OPTIMUM SPEED, MEAN POWER, MEAN TORQUE

\begin{tabular}{c|c|c|c}
$\begin{array}{c}\text { Sea } \\
\text { State }\end{array}$ & $\begin{array}{r}\text { Optimum } \\
\text { Speed (rpm) }\end{array}$ & $\begin{array}{c}\text { Mean } \\
\text { Power (W) }\end{array}$ & $\begin{array}{c}\text { Mean Torque } \\
(\text { Nwm) }\end{array}$ \\
\hline B02 & 1075 & 27110 & 241 \\
\hline B04 & 1200 & 41470 & 330 \\
\hline B06 & 1200 & 38900 & 310 \\
\hline B07 & 1580 & 94680 & 572 \\
\hline B09 & 1390 & 68350 & 470 \\
\hline B12 & 950 & 20490 & 206 \\
\hline B13 & 1518 & 91760 & 577 \\
\hline B15 & 1075 & 27240 & 242 \\
\hline
\end{tabular}

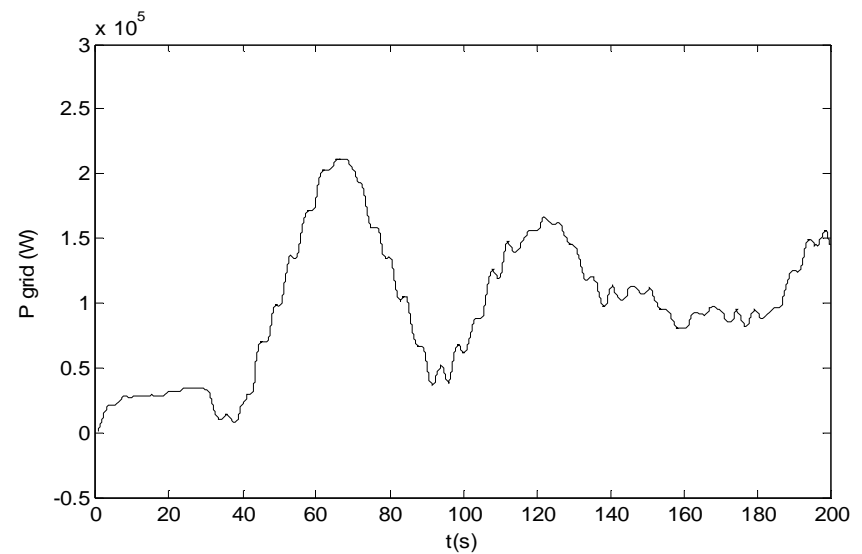

(a)

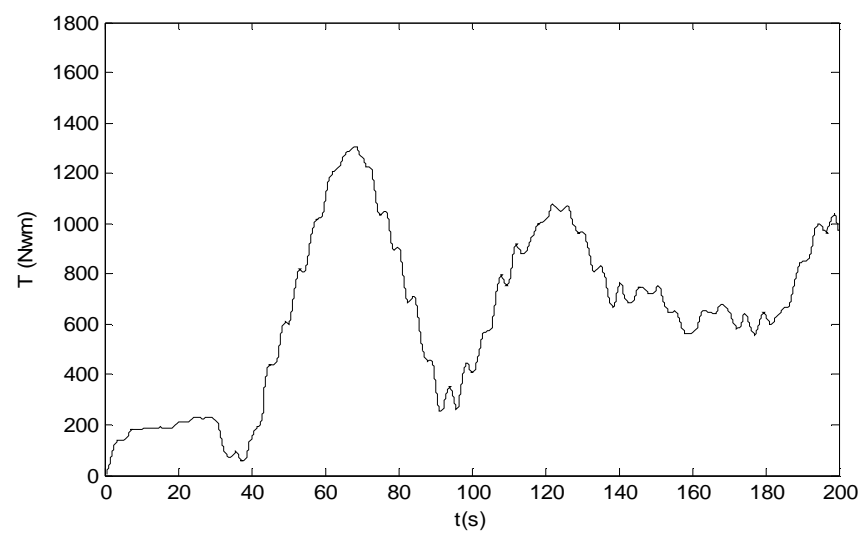

(b)

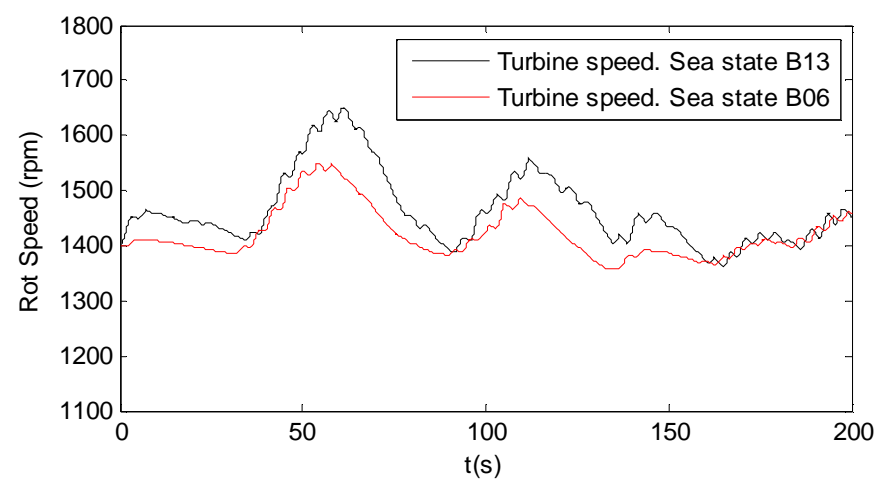

(c)

Fig. 8: Simulation results. Flywheel, constant speed. (a) Electrical power under sea state B13; (b) Electrical torque under sea state B13; (c) Rotational speed for sea states B13 (black) and B06 (red).

shown in Fig. 8(c). The resulting rotational speeds for each sea state agree with the values shown in Table 2, thus optimizing the turbine efficiency. The rest of the waveforms are similar to those shown in Fig. 8(a) and (b). Therefore, this control law smooth the generator torque and power injected into the grid, thereby, 
avoiding the need to overrate the generator and the power converters. In addition, since the rotational speed changes according to the current sea state, the efficiency of the system improves when it is compared with the fixed speed solution described in previous sub-section.

\section{Efficiency and Power Quality Comparison}

This section summarizes, quantifies and compares the main features of the three control laws introduced and analysed thus far. It has been discussed that the inclusion of energy storage systems allows improvement of the power quality of the energy injected into the grid, removing the high power peaks that otherwise would appear. This fact is highlighted in Fig. 11(a). This figure shows a comparison between the powers injected into the grid when the control law introduced in [8] with no-energy storage system and the control laws for ultracapacitors and flywheels (torque-speed control law) introduced in this paper are used. It is evident that the use of energy storage devices together with the proposed control laws can smooth the power injected into the grid. In addition, there is no need to overrate the grid side power converter when these elements are used. Both, ultracapacitors and flywheel, have been dimensioned to produce a similar filtering effect.

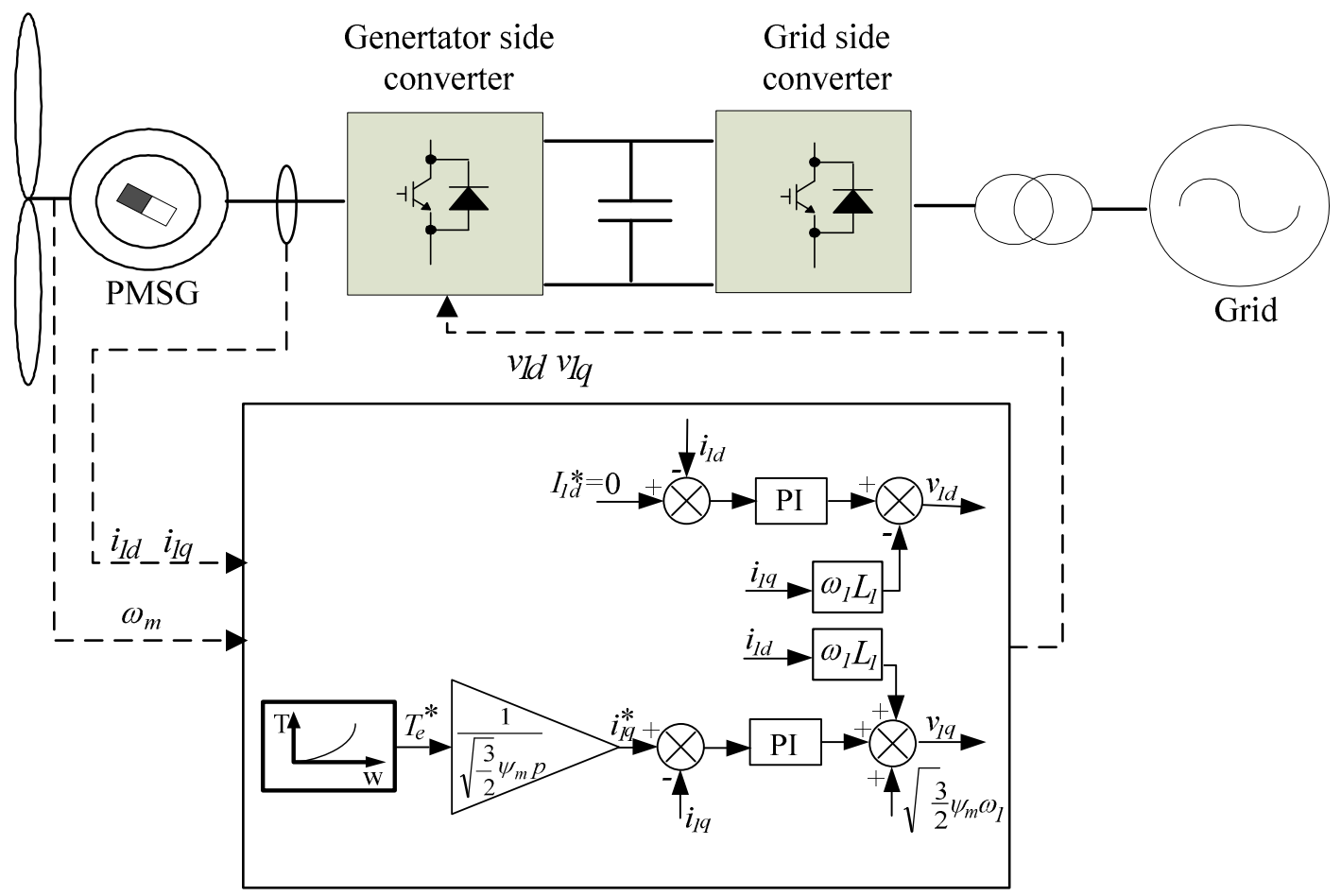

Genertator side converter controller

Fig. 9: Generator side converter controller for a torque-speed curve based controller. $\mathrm{T}_{\mathrm{e}}{ }^{*}$ is the electrical torque reference, $i_{l d}$ and $i_{l q}$ are the reactive and active components of the actual generator current, $I_{l d}{ }^{*}$ and $i_{l d}{ }^{*}$ are the reactive and active current references, $\psi_{m}$ is the magnetic flux, $L_{l}$ is the generator inductance, $\omega_{1}$ the generator electrical frequency, $p$ the number of pair of poles of the generator, and $v_{l d}$ and $v_{l q}$ are the $d q$ components of the voltage at the generator terminals. 


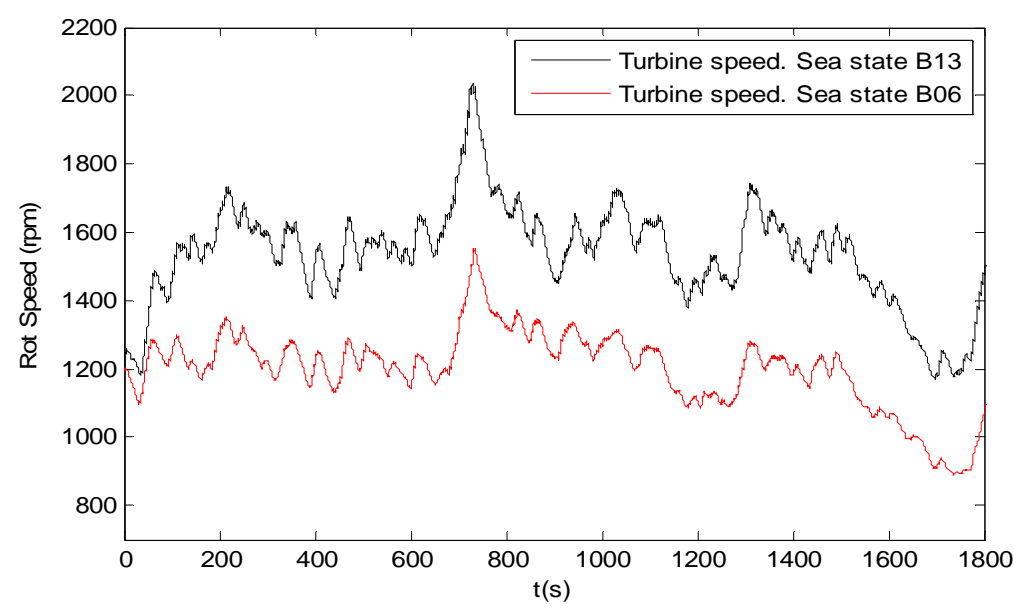

Fig. 10: Simulation results. Flywheel, variable speed for sea state B13 (black) and B06 (red).

The peak-to-average power ratio gives an indication of the electrical power rating required for devices in the PTO system. A system with a large peak-to-average ratio requires larger and more expensive electrical equipment than a corresponding system with a lower peak-to-average ratio, even if both systems generate the same average power. Table 3 compares the peak-to-average power ratio for the different control laws introduced. A considerable reduction of the peak-to-average power ratio is achieved when the energy storage systems, together with the control laws introduced here, are used.

Fig. 11(b) shows a comparison of the generator electrical torque. Only the use of a flywheel has a filtering effect over the electrical torque peaks. There is no difference between using or not ultracapacitors from the generator point of view. Therefore, the generator side power converter needs to be overrated when ultracapacitors are used.

TABLE 3

Peak-to-Average Power Ratio Comparison

\begin{tabular}{c|c|c|c}
$\begin{array}{c}\text { Optimum speed } \\
\text { control law. }\end{array}$ & $\begin{array}{c}\text { Variable } \\
\text { speed in a sea } \\
\text { state basis. } \\
\text { Flywheel. }\end{array}$ & $\begin{array}{c}\text { Fixed } \\
\text { speed. } \\
\text { Flywheel. }\end{array}$ & $\begin{array}{c}\text { Optimum speed } \\
\text { control law. No } \\
\text { storage } \\
\text { elements [8]. }\end{array}$ \\
\hline 3.05 & 2.3 & 3.4 & 6.3 \\
\hline
\end{tabular}

Finally, Table 4 shows a comparison in terms of efficiency of the different control laws introduced here. The efficiency data has been normalized to the efficiency of an OWC device with no storage and controlled with the optimum speed control law introduced in [8], which is used as the benchmark. To calculate the efficiency, the energy production over one year of a single OWC device under the wave climate of Galway Bay has been considered. The reduction on the efficiency shown by the optimum speed 


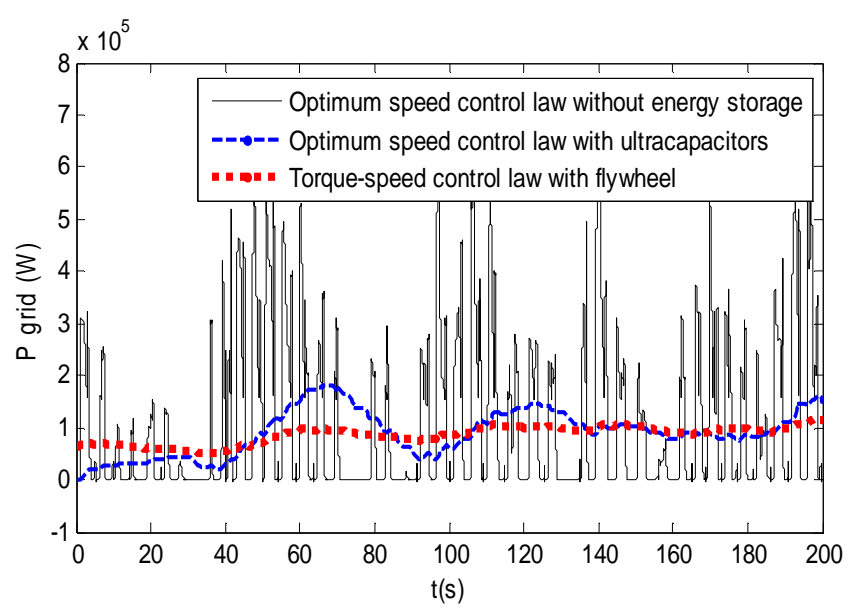

(a)

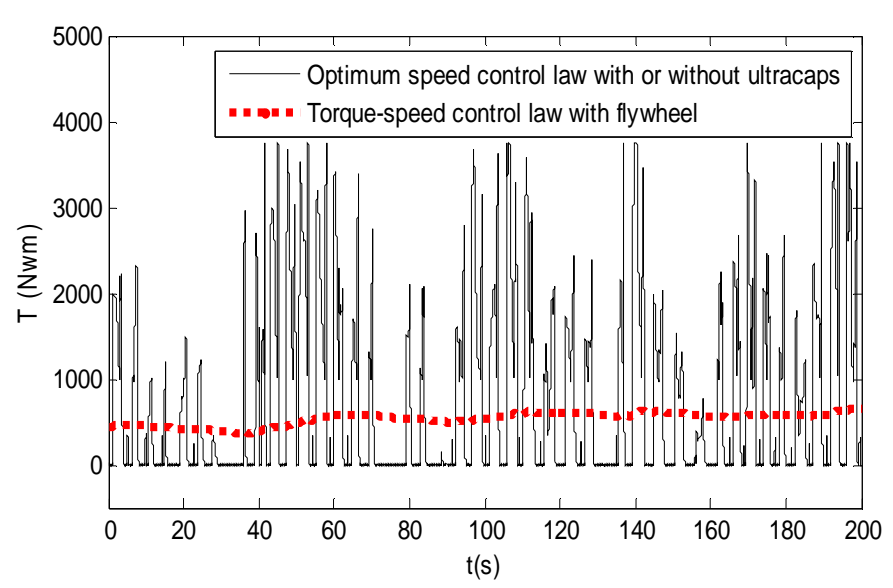

(b)

Fig. 11. (a) Grid power comparison; (b) Electrical torque comparison. Simulation results.

control law with ultracapacitors with regard to the benchmark is associated mainly with the extra losses introduced by the dc/dc converter shown if Fig. 3. The application of the optimum speed control law with ultracapacitors exhibits an increase on the energy production of around $13 \%$ with regard to the variable speed solution for flywheels. It is also shown that, when a flywheel is used, the variable speed solution increases the energy production on around a 5\% with regard to the fixed speed control law.

From these results it is difficult to conclude which is the best solution. As a general conclusion, it can be said that the use of ultracapacitors allows the optimization of the energy production while smoothing the energy injected into the grid. However, the generator and the generator side power converter are under stress. On the other hand, the flywheel allows a reduction in the cost of the power converters because they do not have to withstand high power peaks but the energy production also decreases. A trade-off between these two factors should be achieved. Hybrid solutions including a flywheel and ultracapacitors can also be adopted. They would allow the optimization of the energy captured while avoiding an excessive overrating of the power converters. Even though a study in terms of energy production for hybrid solutions is not conducted here, the control laws introduced are completely general and could be used in these systems.

TABLE 4

ENERGY PRODUCTION PER UNIT OVER ONE YEAR

\begin{tabular}{c|c|c|c}
$\begin{array}{c}\text { Optimum speed control } \\
\text { law. No storage [8]. }\end{array}$ & $\begin{array}{c}\text { Optimum } \\
\text { speed control law. } \\
\text { Ultracapacitors. }\end{array}$ & $\begin{array}{c}\text { Variable speed } \\
\text { in a sea state basis. } \\
\text { Flywheel. }\end{array}$ & $\begin{array}{c}\text { Fixed } \\
\text { speed. } \\
\text { Flywheel. }\end{array}$ \\
\hline 1 & 0.98 & 0.85 & 0.8 \\
\hline
\end{tabular}




\section{Experimental Results}

In order to validate the simulation results and the control strategies presented in previous sections a set of experimental tests have been conducted in a $10 \mathrm{~kW}$ grid-connected rotating test-rig. The experimental platform shown in Fig. 12 comprises a prime mover motor, a flywheel, a generator and a back-to-back converter that connects the generator to the grid. Therefore, fully variable speed tests can be performed. The back-to-back converter is controlled by means of a PLC. The OWC and the Wells turbine behaviour is emulated using a real time emulator that controls the prime motor.

In order to scale the input data to the test-rig scale, the rules of Froude scaling are used. Using this method, the torques, speeds, powers, and mechanical parameters of the system can be scaled between the test rig scale and the full scale system. Fig. 13 compares the experimental (red) and simulation (blue) results obtained when the torque-speed controller is used. These results have been obtained for sea state B13. A flywheel with an inertia of $8.2 \mathrm{kgm}^{2}$ has been employed. Fig. 13(a)-(d) show the pneumatic power, the generator electrical torque, the turbine rotational speed and the power of the generator respectively. Simulation and experimental results match well, thus validating the simulation models used to develop the control laws described in previous sections.

Fig. 14 shows the experimental rotational speed for the sea states B13 and B06. According to the theoretical approach of the torque-speed control law, the speed varies along with the sea state. Finally, Fig. 15 compares the generator electrical torques obtained when the torque-speed control law and the optimum speed control law for a system with ultracapacitors are used. The filtering effect of the flywheel is clearly manifested.

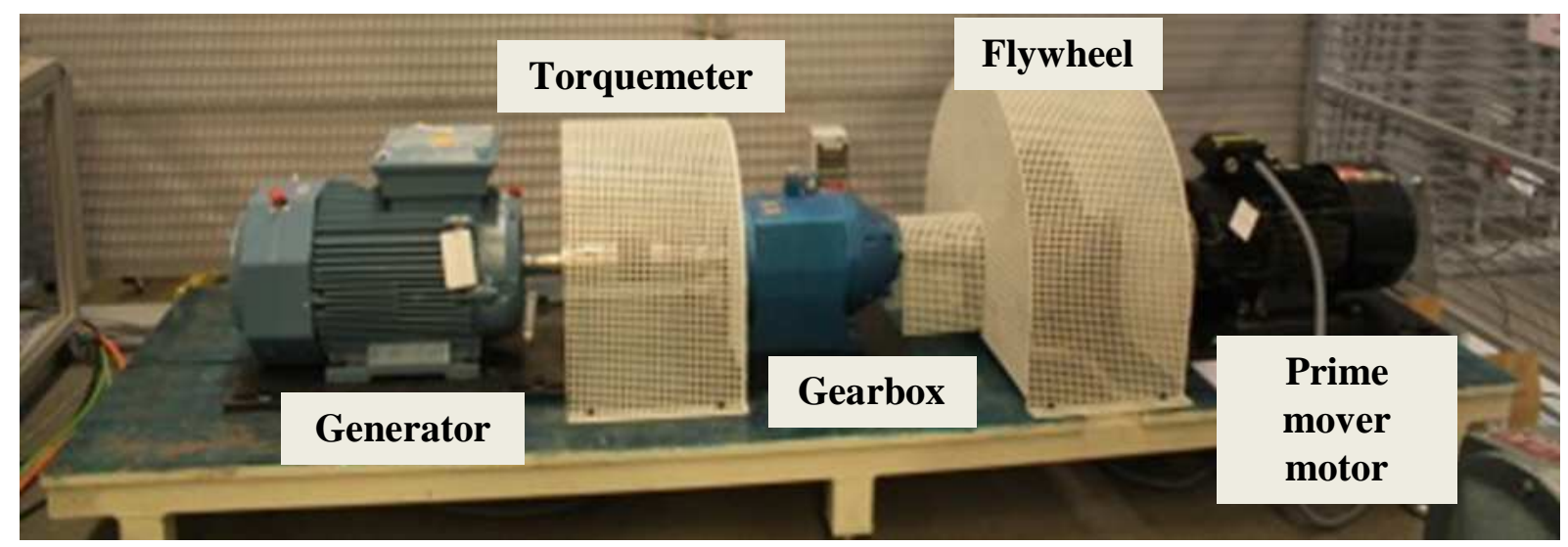

Fig. 12. Electrical PTO test-rig. 


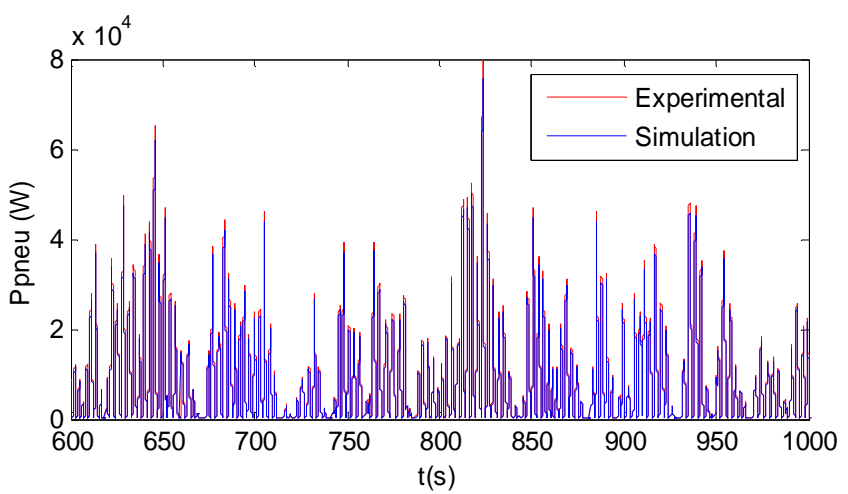

(a)

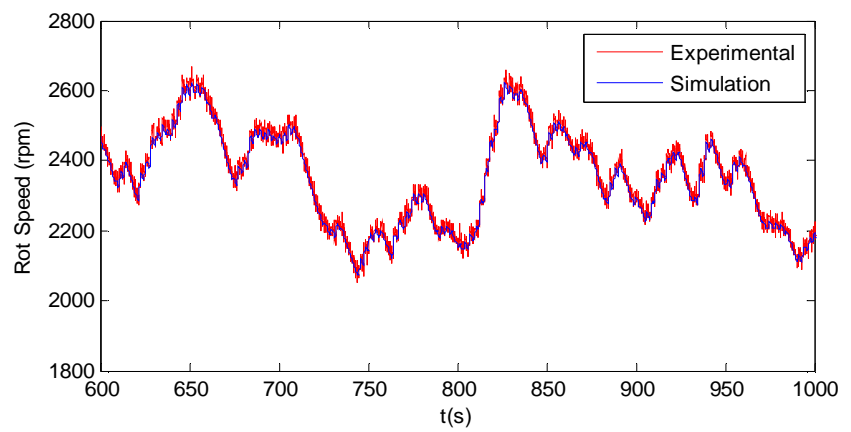

(c)

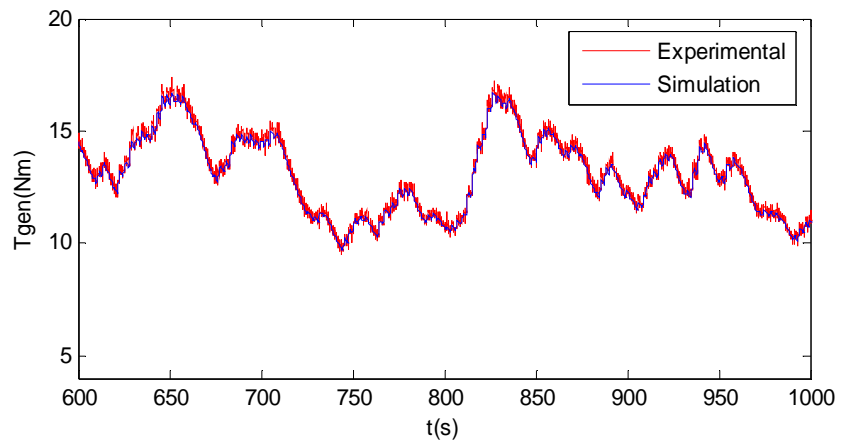

(b)

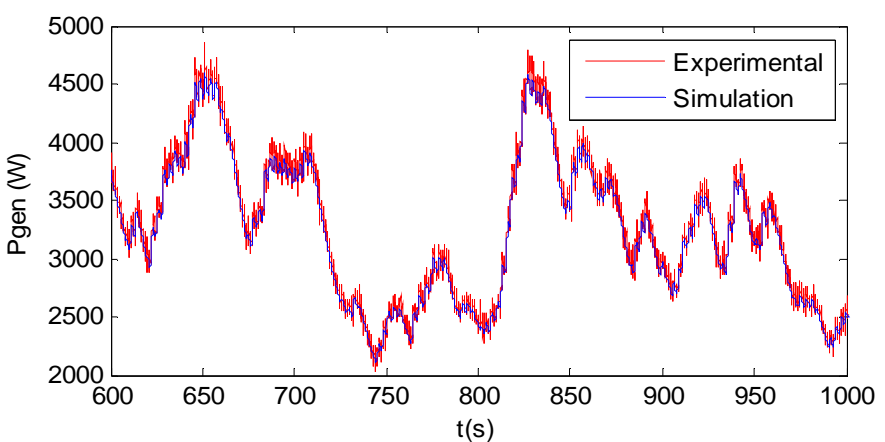

(d)

Fig. 13. (a) Pneumatic power; (b) G enerator electrical torque; (c) Rotational speed; (d) Generator power. Comparison of experimental and simulation results for sea state B13.

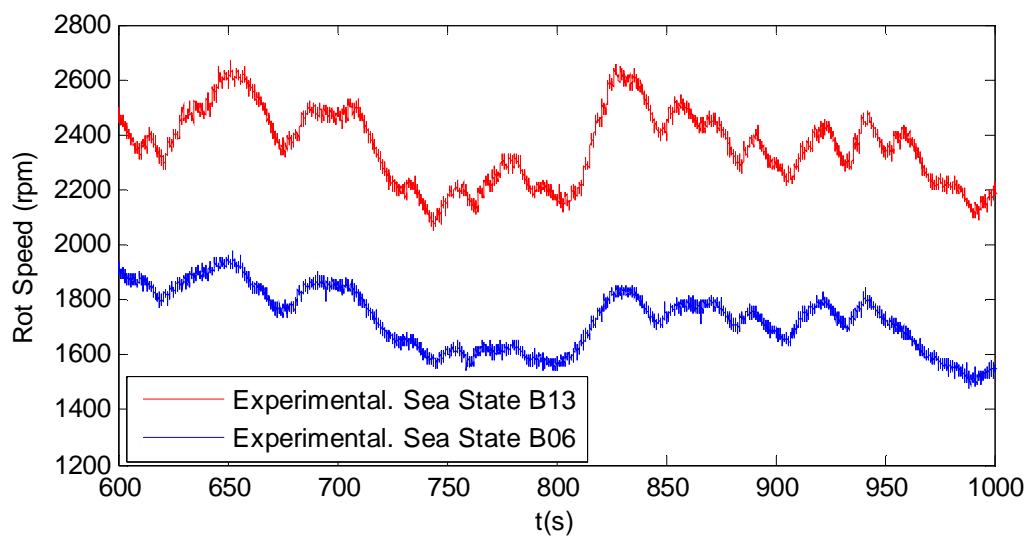

Fig. 14. Rotational speed for sea state B13 and B06; Torque-speed control law.

\section{Conclusion}

The paper proposes three control laws for Wells turbine-based OWC devices that include mechanical and electrical energy storage systems. The first control law is developed for OWC systems that include ultracapacitors as a way to smooth the electrical power injected into the grid. This control law is able to regulate the turbine rotational speed in a wave-by-wave time basis, thus maximizing the turbine efficiency. However, the use of ultracapacitors and the necessity to over-rate the electrical generator and 


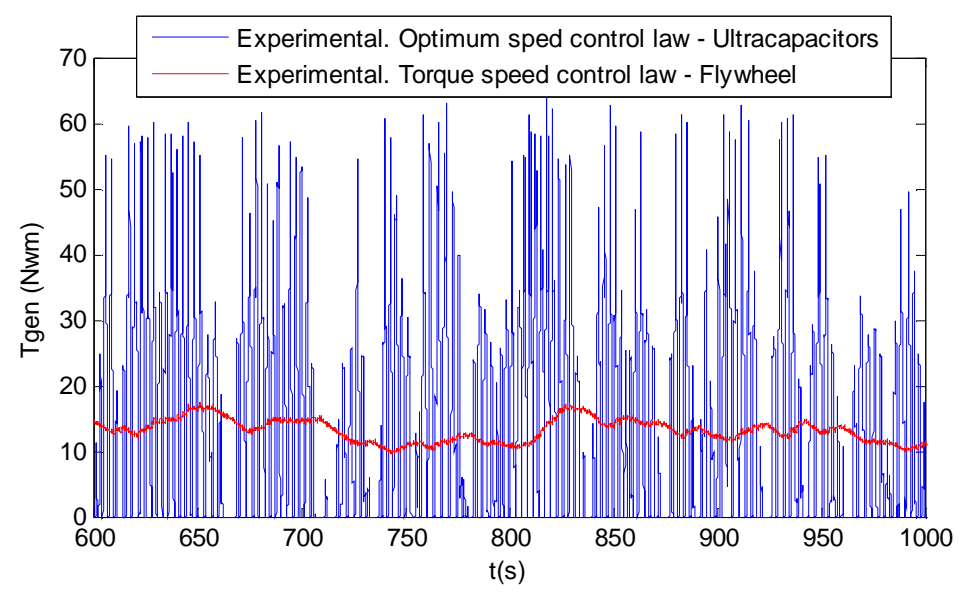

Fig. 15. Generator electrical torque comparison.

the generator-side and dc/dc power converters due to the high peak-to-average power ratio, increase the cost of the electrical system on around $50 \%$. The increase on the initial cost of the PTO is compensated with a growth on the efficiency of up to $13 \%$, with regard to slow variable speed solutions, which makes to recover the increase on the initial investment on about ten years (depending on the wave climate and the energy price of the specific location where the OWC is placed). Additionally, some other aspects that should be taken into consideration when this solution is implemented are:

- Increased reliability risk of adding supercapacitors and more power electronics.

- The necessity of using low inertia systems, very likely relaying on the development of low diameter, high speed and advanced material turbine designs.

Given these considerations and the conclusions above, ultracapacitors are unlikely to be used in the short term but may prove an interesting solution in the medium term.

Two control laws have been proposed to control an OWC with a flywheel. The first control law maintains the system at an optimum constant speed. The main characteristics of this control solution are the simplicity and robustness. These two features make the use of this control strategy appropriate during the first stages of development of an OWC device, where it is interesting to have a robust control solution while validating other system aspects. However, due to its low efficiency, it is not a suitable control law once the system is in operation and its use is expected to be restricted to prototype testing of new devices. The third control law described in the paper allows the variation of the rotational speed on a sea state time basis. It increases the efficiency on about $5 \%$ with regard to the constant speed solution with the same hardware requirements. This solution seems to achieve a good compromise between efficiency, hardware 
requirements and cost. Consequently, among the three control laws introduced, it seems to be the most suitable for today's OWC devices.

\section{Acknowledgments}

This material is based upon works supported by the European Commission funding through the MARINET project (Marine Renewables Infrastructure Network). Financial support from KIC InnoEnergy through the CIPOWER (Controllable and Intelligent Power Components) project is also acknowledged.

\section{References}

[1] Pierre-Henri-Joseph de Girard and Philippe-Henri de Girard, "Divers moyens d'employer les vagues de la mer comme moteurs," Ten Year Invention Patent (No Patent Numbers in France between 1791 et 1844), July 12, 1799.

[2] European Ocean Energy Association, "Industry Vision Paper - 2013," 2013.

[3] US Department Of Energy. (2013, August) Energy Department Invests \$16 Million to Harness Wave and Tidal Energy. [Online]. HYPERLINK "http://energy.gov/articles/energy-department-invests-16-millionharness-wave-and-tidal-energy" http://energy.gov/articles/energy-department-invests-16-million-harnesswave-and-tidal-energy

[4] "Horizon 2020 Work Programme 2014-2015, 10. Secure, clean end efficent energy," European Commission Decision C(2013)8631 of 10 December 2013, 2013.

[5] European Commission, "Communication from the Commission to the European Parliament, the Council, the European Economic and Social Committee and the Committee of the Regions on Blue Energy: Action needed to deliver on the potential of ocean energy in," Communication from the Commission to the European Parliament 2014.

[6] A. F. D. O. Falcao, "Control of an oscillating-water-column wave power plant for maximum energy production," Applied Ocean Research, vol. 24, pp. 73-82, Apr. 2002.

[7] J. Cruz, "Ocean Wave Energy: Current Status and Future Perspectives," Springer, 2008.

[8] S. Ceballos, J. Rea, I. López, J. Pou, E. Robles. and D. L. O'Sullivan, "Efficiency Optimization in Low Inertia Wells Turbine Oscillationg Water Column Devices," IEEE Trans. Energy Convers., vol. 28, pp. 553-564, Sept. 2013.

[9] M. Alves, M. Vicente, A. J. N. A. Sarmento, and M. Guerinel, "Implementation and Verification of a Time Domain Model to Simulate the Dynamics of OWCs," in Proc. of the 9th European Wave and Tidal Energy Conference (EWTEC 2011), Southampton, UK, 2011.

[10] D. Vassalos, "Physical modelling and similitude of marine structures," Ocean Engineering, vol. 26, pp. 111123, Aug. 1998.

[11] E. Tedeschi and M. Molinas, "Tunable Control Strategy for Wave Energy Converters with Limited Power Take-Off Rating," IEEE Trans. Ind. Electron., vol. 59, no. 10, pp. 3838-3846, Oct. 2012.

[12] E. Tedeschi, M. Carraro, M. Molinas, and P. Mattavelli, "Effect of Control Stratgies and Power Take-Off Efficiency on the Power Capture From Sea Waves," IEEE Trans. Energy Convers., vol. 26, no. 4, pp. 10881098, Dec. 2011.

[13] F. Wu, X. Zhang, and P. Ju, "Application of the battery energy storage in wave energy conversion system," in Proc. International Conference on Sustainable Generation and Supply (SUPERGEN'09), pp. 1-4, Nanjing, China, Apr. 2009.

[14] W. Li, G. Joós, and C. Abbey, "A parallel bidirectional dc/dc converter topology for energy storage systems in wind applications," in Proc. Conference Record of the 2007 IEEE Industry Applications Conference, pp. 171- 
185, New Orleans, USA, Sept. 2007.

[15] S. Raghunathan, "The Wells air turbine for wave energy conversion," Progress in Aerospace Sciences, vol. 31, pp. 335-386, Jan. 1995.

[16] M. J. Tucker and E. G. Pitt, "Waves in Ocean Engineering," Elsevier Ocean Engineering Series, Nov. 2001. 